\title{
Survival of Phytophthora ramorum in Recirculating Irrigation Water and Subsequent Infection of Rhododendron and Viburnum
}

\author{
S. Werres and S. Wagner, Federal Biological Research Center for Agriculture and Forestry, Institute for Plant Pro- \\ tection in Horticulture, Messeweg 11/12, D-38104 Braunschweig, Germany; T. Brand, Chamber of Agriculture \\ Niedersachsen, Hogen Kamp 51, D-26160 Bad Zwischenahn, Germany; K. Kaminski, Federal Biological Research \\ Center for Agriculture and Forestry, Braunschweig, Germany; and D. Seipp, Chamber of Agriculture Niedersachsen, \\ Bad Zwischenahn, Germany
}

\begin{abstract}
Werres, S., Wagner, S., Brand, T., Kaminski, K., and Seipp, D. 2007. Survival of Phytophthora ramorum in recirculating irrigation water and subsequent infection of Rhododendron and Viburnum. Plant Dis. 91:1034-1044.

Phytophthora ramorum was studied in an open air simulation system with nine separate container stands each connected to its own water collection system. The water in these reservoirs was inoculated with $P$. ramorum and then used for overhead irrigation over the course of the season to study the spread of the pathogen and development of P. ramorum blight in Rhododendron and Viburnum spp. P. ramorum could infect plants through the use of contaminated irrigation water, with the maximum amount of infection of Rhododendron spp. less than 19\%. In the 2 years of the study, symptom onset occurred 8 and 16 days, respectively, after water was first inoculated. The disease rate proportion of infected plants developing symptoms varied with year and season. In both years, the pathogen was detected in the water reservoirs over the course of the growing season.
\end{abstract}

Additional keywords: disease symptoms, latent infection, nursery

Since its original isolation in 1993, Phytophthora ramorum has become an important pathogen of quarantine significance. $P$. ramorum has been detected not only in diseased plants but also in soil and in water samples from rivers as well as from recirculation water in nurseries $(15,16)$.

To economize water consumption in container nurseries, surplus water from irrigation and natural rain is collected from the container stands via drains and special drainage systems and stored in special reservoirs. From these reservoirs, the water is reused for irrigation. It is estimated that more than $90 \%$ of the surplus water can be recovered (10) and recirculated in commercial systems. This significantly reduces demand for fresh water, thus decreasing expenses, and prevents probably existing nutrients and pesticides from stands from entering the groundwater.

It is well known that contaminated recirculation water is a major means of dissemination of Phytophthora spp. However, there is little known about the survival of

Corresponding author: S. Werres

E-mail: S.Werres@BBA.de

Accepted for publication 27 March 2007.

doi:10.1094/PDIS-91-8-1034

This article is in the public domain and not copyrightable. It may be freely reprinted with customary crediting of the source. The American Phytopathological Society, 2007.
$P$. ramorum in water or whether plants can become infected when infested water is used to irrigate plants. In order to understand disease spread and develop control methods, it is of great importance to know whether irrigation with contaminated recirculation water can result in infection with $P$. ramorum and how long it takes until disease symptoms appear. The results should provide information for risk assessment of $P$. ramorum-contaminated water in practical uses in nurseries and for the development of control methods.

\section{MATERIALS AND METHODS}

Simulation system. The simulation system was established outdoors in the research fields of the Bad Zwischenahn Research Institute, Germany. This system consisted of nine separate container areas (stands) of approximately $15 \mathrm{~m}^{2}$ each with its own water recirculation system (Fig. 1). As is standard practice in commercial container nurseries, the potted plants were arranged on MyPex ground cover. From each stand, the surplus water from irrigation and natural rain was collected in a plastic water reservoir with a capacity of approximately 1,000 liters. The reservoirs were not covered. Each container stand had its own reservoir where the runoff water from the corresponding container stand was collected and from which the water was drawn for overhead irrigation with sprinkler heads. The reservoirs were filled with well water and pond water and replenished during the season when necessary. During the winter period of 2004-05, the water remained in the noncovered reservoirs according to commercial practice. Water quality was comparable with that used by growers in northern Germany. Chemical data of the water were analyzed by an official laboratory of the Chamber of Agriculture in Lower Saxony (LUFA Nord-West). The data (not presented) showed that the water was of the quality demanded for nurseries $(1,7,20)$. Because it was an open-air simulation system, the recycled water mixed with natural rain water during the season.

The simulation system was first used for a pretest with P. ramorum in August 2003. The arrangement of treatments (Fig. 1) and the inoculum density was similar to 2004 . During this pretest, the water reservoirs were inoculated but no plants were irrigated with the contaminated water. Water samples taken in December 2003 showed that $P$. ramorum was present not only in the infested but also in the noninfested water reservoirs. Four months later (28 April 2004), the pathogen could be trapped from the six infested reservoirs but no longer from the three control reservoirs (see below).

Plant material and cultivation. In 2004, rooted cuttings of Rhododendron cv. Cunningham's White were potted into 0.7liter pots. The substrate used was peat with limestone $\left(2.0 \mathrm{~g} \mathrm{liter}^{-1}\right)$. The rooted cuttings were produced at the $\mathrm{Bad}$ Zwischenahn Research Centre and a local nursery. In all, 328 of these potted plants were placed in carrying trays in each container area at the beginning of May. For nutrition, the coated slow release fertilizer Osmocote Exact Standard 5-6M (3.0 or 4.0 $\mathrm{g} \mathrm{liter}^{-1}$ ) and the microelement fertilizer Radigen (100 mg liter ${ }^{-1}$ ) were mixed into the substrate before planting. No additional fertilization was done. Osmocote Exact Standard 5-6M was used at the lower rate for the cuttings from the local nursery because their root systems were smaller than those from the Bad Zwischenahn Research Centre. The plants remained on the container stands until March 2005.

In 2005, 333 rooted cuttings of Rhododendron cv. Cunningham's White in 0.7liter pots and 50 Viburnum plicatum cv. Mariesii in 2-liter pots were placed on 
each container stand on 12 to 13 May. All plants originated from the Bad Zwischenahn Research Centre. The Rhododendron plants were fertilized as in 2004. For the Viburnum plants, a higher dose of limestone was mixed into the substrate $\left(5.0 \mathrm{~g} \mathrm{liter}^{-1}\right)$ due to the needs of this species.

In both years, the plants were arranged randomly on the container stands.

Inoculum and inoculation of water reservoirs and plants. $P$. ramorum isolate BBA 9/95 (Ex-type strain, German origin) was cultivated on 5\% carrot juice agar (CJA) according to Werres et al. (19) at $20^{\circ} \mathrm{C}$ in the dark for 14 days. To infest the reservoirs, actively growing cultures in 9$\mathrm{cm}$-diameter petri dishes were macerated using a scalpel and mixed thoroughly with water and sediment in each reservoir.

Two different inoculum densities were chosen according to the results of an earlier study (S. Werres, unpublished data). In 2004 and 2005, the low-inoculum-density treatment was 12.5 petri dish cultures ( 9 $\mathrm{cm}$ in diameter) per reservoir. In 2004, the high-inoculum-density treatment was 25 petri dish cultures per reservoir and, in 2005 , it was 50 petri dish cultures. In both years, the noninfested control treatment was 12.5 petri dishes of sterile CJA. Each treatment was replicated three times as three independently infested reservoirs with their associated container stands. The arrangement of the inoculum density was the same in both years (Fig. 1). Plants were irrigated from the reservoirs with sprinklers beginning 1 day after infesting the reservoirs in 2004 and beginning the same day in 2005. At the inoculation dates, the reservoirs contained 1,000 liters of water. Subsequent timing of irrigation followed commercial practice and depended on temperature and rainfall; during periods with high temperatures and low rainfall, it could be as much as twice a day whereas, in periods with lower temperatures or heavy rainfall, it could be no more than as infrequently as only twice a week. During both experimental periods (May 2004 to March 2005 and May to November 2005), the last irrigation was in the middle of October. Attempts to measure water volume used per irrigation failed because particles in the water clogged the water meter and the filter, which was connected upstream from the water meter.

Assessment of disease rate and plant development. The occurrence of disease symptoms on the upper parts of the plants was assessed visually once a week. Ten different assessment categories were used, as follows: no symptoms, wilting of the twig tip, wilting of the whole plant, leaves shriveled and pale green, plant appearing dead, leaf spots, discoloration of petiole and midrib, necrotic lesions on leaves and discoloration of the petiole and the midrib, discoloration of the stem (apart from the stem base), and discoloration at the stem base.

Discoloration of the roots was assessed only during the experimental period May until November 2005: during the season on plants with disease symptoms on the upper plant parts and on all plants removed from the container stands in November 2005 (see below).

The pattern of disease spread within a single container area also was examined.
As soon as disease symptoms occurred, the infected plants were taken to the laboratory for direct isolation.

To evaluate differences in plant quality, growth characteristics were calculated on all remaining plants on the container stands in November 2005. For the Rhododendron plants, the length of the main shoot was measured and the number of lateral shoots was counted. For the Viburnum plants, the number of lateral shoots of first and second range was assessed.

Assessment of survival in the water reservoirs. Survival of $P$. ramorum in the water reservoirs was assayed using the Rhododendron leaf bait test (14). In 2004, water was assayed in April (prior to inoculation), July, and October (Table 1). In 2005 , reservoirs were assayed at seven dates from April (the beginning of the season) to the end of October (just prior to plant removal). The bait test consisted of 10 Rhododendron leaves placed directly onto the water surface of each reservoir. As soon as spots were visible, but no later than 15 days after baiting, leaves were removed from the reservoir and cultured on carrot piece agar (CPA) according to Themann et al. (14). Organisms isolated from the leaves were identified morphologically and by polymerase chain reaction (PCR; 4). If the 10 bait leaves did not develop any symptoms, they were macerated and a subsample tested with PCR.

Assessment of plant infection. As soon as symptomatic plants were detected, they were removed from the container stands to prevent spread of $P$. ramorum via infected plants. They were taken to the laboratory and pieces of symptomatic leaves and
Sprinkling

system and water recirculation

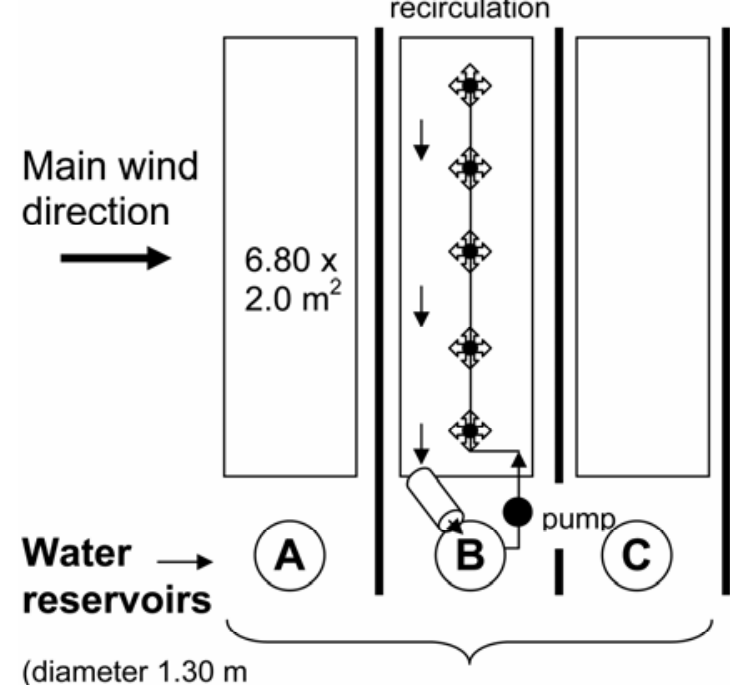

(diameter $1.30 \mathrm{~m}$ depth $0.90 \mathrm{~m}$ ) not inoculated
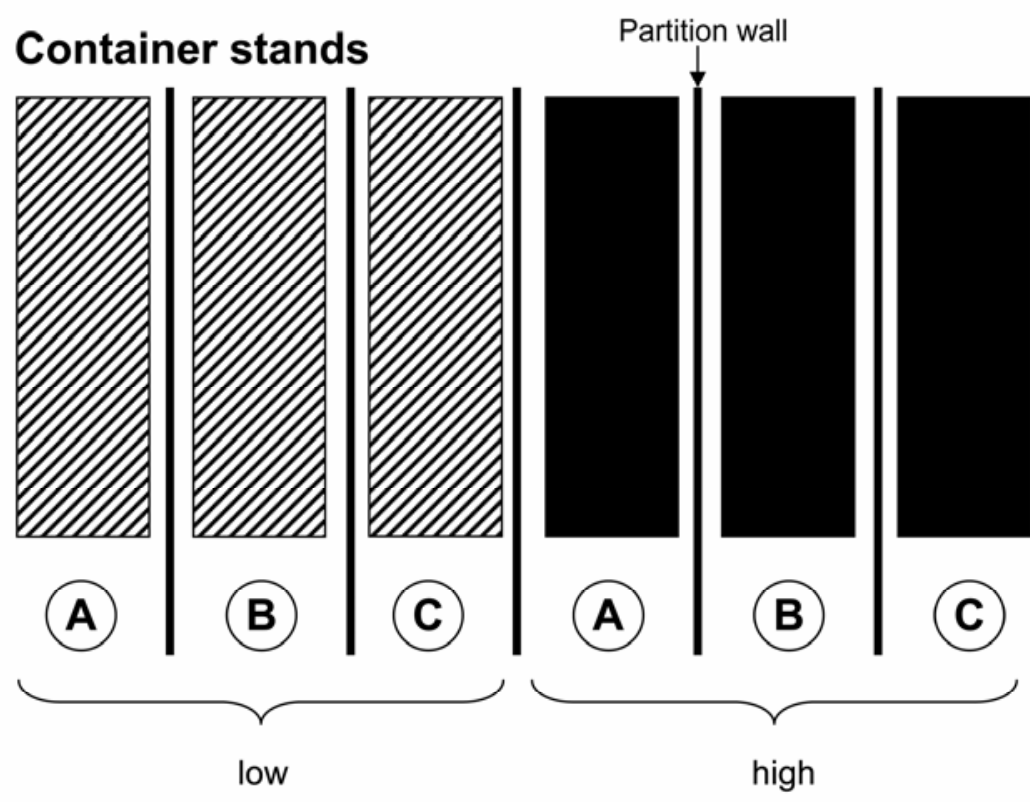

\section{Inoculum density}

Fig. 1. Simulation system and inoculum arrangement for all experiments. Individual container areas (replications A to C) were independent and designed so that the surplus water could only drain back to the reservoir for that replication. 
twigs were plated on CPA. If plants showed symptoms of wilting without lesions, root samples were taken and baited using the Rhododendron leaf bait test.

To detect latent infection in asymptomatic plants, plants from each container stand were removed for sampling at the end of the experiment. In the 2004 trial, 10 Rhododendron plants per container stand were removed on 15 March 2005; in the 2005 trial, 100 Rhododendron plants per container stand and all the Viburnum plants Rhododendron plants in 2005 were sampled according to their position relative to a previously sampled symptomatic plant: 50 that were next to a symptomatic plant and 50 that were at least two pots away a symptomatic plant. Due to the very low number of diseased Viburnum plants observed during the season (only two in a single block), no distinctions based on position were made among Viburnum plants sampled. After plants were brought to the laboratory, a 2-cm section was taken through the center of each root ball along the horizontal plane. Rootball sections from the same plant position and the same container stand were combined into two composite samples. A volume of $400 \mathrm{ml}$ of were removed on 11 November 2005. The

each sample then was flooded and baited with Rhododendron leaves. Leaf baits were removed as soon as leaf spots appeared. Bait leaves without disease symptoms were removed after 7 days. From all leaves, three pieces per leaf were plated on CPA. P. ramorum colonies were identified by PCR (see above).

Measurement of air and water temperatures and sum of global radiation and precipitation. Air and water temperatures as well as global radiation and precipitation were measured continuously in 2004 and 2005. All data were measured using an official meteorological station located near the simulation system except water temperature, which was measured in one of the control treatment water reservoirs.

Statistical calculation. To test for any significant separation of groups, a one- or two-way analysis of variance followed by the Tukey test or the Kruskal-Wallis test (Sigma Stat 9.0, Jandal Scientific) was used. The level of significance was set at $\alpha=0.05$.

\section{RESULTS}

Detection of $P$. ramorum in the water reservoirs. In both years, the pathogen

Table 1. Baiting period of Rhododendron leaves in water reservoirs and average water temperatures

\begin{tabular}{lccc}
\hline & & \multicolumn{2}{c}{ Average temperatures $\left({ }^{\circ} \mathbf{C}\right)^{\mathbf{a}}$} \\
\cline { 2 - 4 } Year, date & Period (days) & Before & During \\
\hline 2004 & 15 & & 13.8 \\
13-28 April & 7 & 20.9 & 21.1 \\
28 July-4 August & 7 & 9.0 & 11.0 \\
22-29 October & & & 14.4 \\
2005 & 11 & 9.9 & 21.1 \\
26 April-7 May & 5 & 15.9 & 19.7 \\
25-30 May & 6 & 21.2 & 19.8 \\
28 June-4 July & 6 & 17.5 & 16.8 \\
26 July-1 August & 6 & 19.2 & 12.8 \\
23-29 August & 7 & 14.4 & 10.1 \\
27 September-4 October & 11 & 11.7 & \\
31 October-11 November & & & \\
\hline
\end{tabular}

${ }^{\mathrm{a}}$ Before $=$ the week before the baiting period and During = during the baiting period. was detected in water samples taken over the course of the growing season (Table 2).

In $2004, P$. ramorum could be detected in all infested reservoirs at the end of April before the Rhododendron plants were placed on the container stands in May. The pathogen also could be trapped with the bait leaves in summer and autumn 2004 in the infested water reservoirs. In 2005, the situation in these reservoirs was different. The results of the first Rhododendron leaf test in April to May 2005 showed that $P$. ramorum also had survived the winter. However, at the end of May, $P$. ramorum could be detected in only three of the six infested water reservoirs and only with PCR. At the beginning of August, detection of $P$. ramorum was positive in only one of the low-inoculum-density reservoirs, but in all three reservoirs with high inoculum density. From the end of August until November, P. ramorum was present in all six infested reservoirs.

The noninfested reservoirs also became contaminated with $P$. ramorum. The bait test from November to December 2003 (pretrial) showed that the pathogen was present in all three reservoirs. However, unlike in the infested reservoirs, it could not be trapped after the winter period 2003-04 at the end of April 2004. In August, detection was possible with PCR but not by direct isolation from the bait leaves. In October 2004, $P$. ramorum could not be detected any longer in these reservoirs. In 2005, the pathogen could be detected only in May and only by PCR. At all subsequent sampling dates through the end of the year, $P$. ramorum could not be detected in the noninfested reservoirs.

The reservoirs were contaminated not only with $P$. ramorum but also with another Phytophthora sp. and with Pythium undulatum (Table 2). In November to December 2003, another Phytophthora sp. was detected in two reservoirs of the noninfested treatment. It could not be detected during any of the subsequent sampling

Table 2. Detection of Phytophthora ramorum in the water reservoirs

\begin{tabular}{|c|c|c|c|c|c|c|c|c|c|c|c|c|c|c|c|c|c|c|c|c|c|}
\hline \multirow[b]{4}{*}{$\operatorname{Dens}^{b}$} & \multirow[b]{4}{*}{$\operatorname{Res}^{c}$} & \multicolumn{20}{|c|}{ Date of removal of bait leaves ${ }^{a}$} \\
\hline & & \multicolumn{6}{|c|}{2004} & \multicolumn{14}{|c|}{2005} \\
\hline & & \multicolumn{2}{|c|}{28 April } & \multicolumn{2}{|c|}{4 August } & \multicolumn{2}{|c|}{29 October } & \multicolumn{2}{|c|}{7 May } & \multicolumn{2}{|c|}{30 May } & \multicolumn{2}{|c|}{4 July } & \multicolumn{2}{|c|}{1 August } & \multicolumn{2}{|c|}{29 August } & \multicolumn{2}{|c|}{4 October } & \multicolumn{2}{|c|}{7 November } \\
\hline & & DI & PCR & DI & PCR & DI & PCR & DI & PCR & DI & PCR & DI & PCR & DI & PCR & DI & PCR & DI & PCR & DI & PCR \\
\hline \multirow[t]{3}{*}{ NI } & A & $\varnothing$ & $\varnothing$ & $\varnothing$ & + & $?$ & $\varnothing$ & $?$ & + & $?$ & $\varnothing$ & $?$ & $\varnothing$ & $\varnothing / \mathrm{X}$ & $\varnothing$ & $\varnothing / \mathrm{X}$ & $\varnothing$ & $\varnothing / \mathrm{X}$ & $\varnothing$ & $\varnothing / \mathrm{X}$ & $\varnothing$ \\
\hline & $\mathrm{B}$ & $\varnothing$ & $\varnothing$ & $\varnothing$ & + & $?$ & $\varnothing$ & $\varnothing$ & + & $?$ & $\varnothing$ & $\varnothing$ & $\varnothing$ & $\varnothing / \mathrm{X}$ & $\varnothing$ & $\varnothing / \mathrm{X}$ & $\varnothing$ & $\varnothing / \mathrm{X}$ & $\varnothing$ & $\varnothing / \mathrm{X}$ & $\varnothing$ \\
\hline & $\mathrm{C}$ & $\varnothing$ & $\varnothing$ & $\varnothing$ & + & $\varnothing$ & $\varnothing$ & $\varnothing / \mathrm{X}$ & + & $?$ & $\varnothing$ & $?$ & $\varnothing$ & $\varnothing / X$ & $\varnothing$ & $\varnothing / X$ & $\varnothing$ & $\varnothing / X$ & $\varnothing$ & $\varnothing / X$ & $\varnothing$ \\
\hline \multirow[t]{3}{*}{ Low } & A & + & + & + & + & + & + & + & + & $?$ & + & + & + & $+/ \mathrm{X}$ & + & $\varnothing / X$ & + & $+/ \mathrm{X}$ & + & + & + \\
\hline & B & + & + & + & + & + & + & $\varnothing$ & + & $?$ & + & + & $\varnothing$ & $\varnothing / X$ & $\varnothing$ & $+/ \mathrm{X}$ & + & + & + & $+/ \mathrm{X}$ & + \\
\hline & $\mathrm{C}$ & + & + & + & + & + & + & $\varnothing$ & $\varnothing$ & $?$ & $\varnothing$ & $\varnothing$ & $\varnothing$ & $\varnothing / \mathrm{X}$ & $\varnothing$ & $+/ \mathrm{X}$ & + & $+/ \mathrm{X}$ & + & + & + \\
\hline \multirow[t]{3}{*}{ High } & A & + & + & + & + & + & + & $\varnothing / X$ & + & $?$ & $\varnothing$ & $?$ & $\varnothing$ & $+/ \mathrm{X}$ & $\varnothing$ & $+/ \mathrm{X}$ & + & $+/ X$ & + & + & + \\
\hline & B & $\varnothing$ & + & + & + & + & + & $?$ & + & $?$ & + & + & $\varnothing$ & $+/ \mathrm{X}$ & + & $?$ & + & $+/ \mathrm{X}$ & + & + & + \\
\hline & $\mathrm{C}$ & + & + & + & + & + & + & $?$ & + & $\varnothing$ & $\varnothing$ & + & + & + & + & $+/ \mathrm{X}$ & + & $+/ \mathrm{X}$ & + & + & + \\
\hline
\end{tabular}

${ }^{a} \mathrm{DI}=$ direct isolation from the bait leaves, PCR = polymerase chain reaction from the agar cultures and from the bait leaves, $\varnothing=$ no detection of $P$. ramorum or another Phytophthora sp., + = detection of $P$. ramorum, $?=$ separation between $P$. ramorum and Pythium undulatum not possible, and $\mathrm{X}=$ detection of $P$. undulatum.

${ }^{\mathrm{b}}$ Density = inoculum density and NI = not inoculated.

${ }^{\mathrm{c}}$ Res $=$ water reservoir. 
dates in 2004 and 2005. In 2005, nearly all water reservoirs were contaminated with $P$. undulatum. The contamination rates were highest between May and October. $P$. undulatum has a very fast growth rate and also produces large chlamydospores. High contamination rates of the bait leaves with this Pythium sp. made direct isolation of Phytophthora ramorum in some of the samples difficult.

Baiting periods and temperatures in the water reservoirs. Leaf baits were left in reservoirs until symptoms developed, which took a relatively long time in April 2004, April to May 2005, and October to November 2005 (Table 1). During these periods, the average water temperatures in the reservoirs was below $15^{\circ} \mathrm{C}$ the week before the Rhododendron leaves were placed on the water surface and during the baiting period (Table 1). In summer and early autumn, the baiting period was less than 7 days. During these periods, the average temperatures was above $15^{\circ} \mathrm{C}$. There were two exceptions. The baiting period in October 2004 was also very short but the average temperatures were very low and the interval at the end of September to the beginning of October 2005 was also very short, with an average temperature of $14.4^{\circ} \mathrm{C}$ the week before and $12.8^{\circ} \mathrm{C}$ during the baiting period.

Total number of diseased plants and character of disease symptoms. Rhododendron. Diseased plants occurred in nearly all container stands. $P$. ramorum was not detected in all symptomatic plants, however (see below and Fig. 2). In 2004, the highest number of diseased plants (10.6\%, average of container stand A to C) came from the low-inoculum-density reservoirs. On the container stands with high inoculum density, on average, $6.6 \%$ of the Rhododendron plants showed disease symptoms, and $2.3 \%$ of the Rhododendron plants which had been irrigated with noninfested water also showed disease symptoms. Due to the high variability in the replicates, only the values for the lowinoculum-density reservoirs differed significantly from the noninfested treatment. In 2005, the highest number of symptomatic plants was observed in the highinoculum-density treatment: an average of 14.7 compared with $9.1 \%$ for the lowinoculum-density plants. Again, there also were symptomatic Rhododendron plants in the noninfested treatment, but the average number was very low $(0.5 \%)$. In 2005 , only the values for the high-inoculumdensity reservoirs differed significantly from the noninfested treatment.

Those symptomatic Rhododendron plants which were infected with $P$. $r a$ morum or with a mix of pathogens (see below) exhibited several types of symptoms. In 2004 and in 2005, necrosis at the stem base was the most frequent disease symptom (73 to $97.8 \%$ of the symptomatic plants). In 2005, most of these plants also showed disease symptoms on the oldest leaves close to the pot-soil surface $(68.7 \%$ in the low and $70.3 \%$ in the high inoculum density). Leaf spots occurred rarely in comparison with the discoloration starting at the petiole and spreading to the midrib. Very often, the midrib appeared yellow. Unspecific symptoms such as poor root development or discoloration on the leaf edges also occurred on some plants. Very often, several symptoms occurred on a single plant. Only a single Rhododendron plant with disease symptoms on the upper parts of the plant (stem base necrosis) had discolored roots; it was in the low-inoculumdensity treatment on 19 August 2005. Of the Rhododendron plants with aboveground symptoms, only a single plant (from a noninfested container stand on 1 July 2005) showed root discoloration. From the latter, $P$. ramorum could not be isolated.

Plants from which $P$. cinnamomi was detected exhibited mainly a stem base necrosis. Different symptoms were displayed by plants infected with Pythium undulatum: yellowing of leaf petiole and midrib, and leaf spots or discoloration at the stem base that seemed to be associated with the cut (wound infection). It was not possible to distinguish infection caused by $P h y$ tophthora ramorum from $P$. cinnamomi or from Pythium undulatum based on disease symptoms.

Viburnum. Only a very low number of Viburnum plants developed disease symptoms during the season: three plants in the noninfested treatment, three in the lowinoculum-density, and two in the highinoculum-density treatment. Most of these plants died due to poor root development. However, root discoloration was not observed. Only two of the diseased Viburnum plants tested positive for Phytophthora ramorum (see below). These two plants showed leaf spots and poor root development.

Diseased plants with positive $P$. ramorum detection. Rhododendron.

Experimental period May 2004 - March 2005

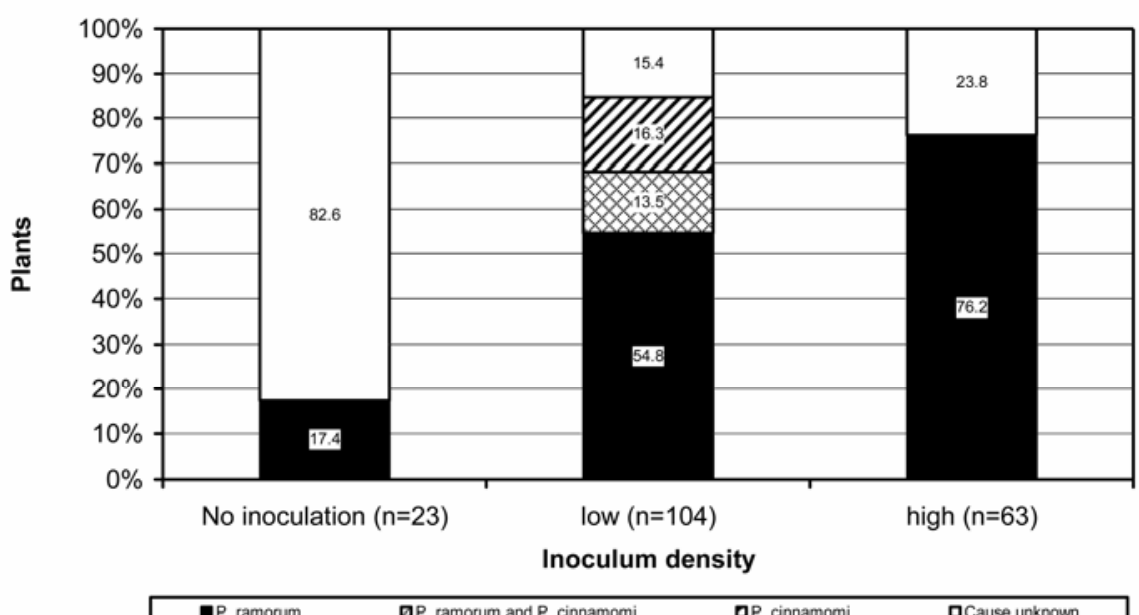

$\begin{array}{llll}\text { Q } P \text {. ramorum } & \text { QP. ramorum and } P \text {. cinnamomi } & \text { QP. cinnamomi } & \text { QCause unknown }\end{array}$

Experimental period May - November 2005

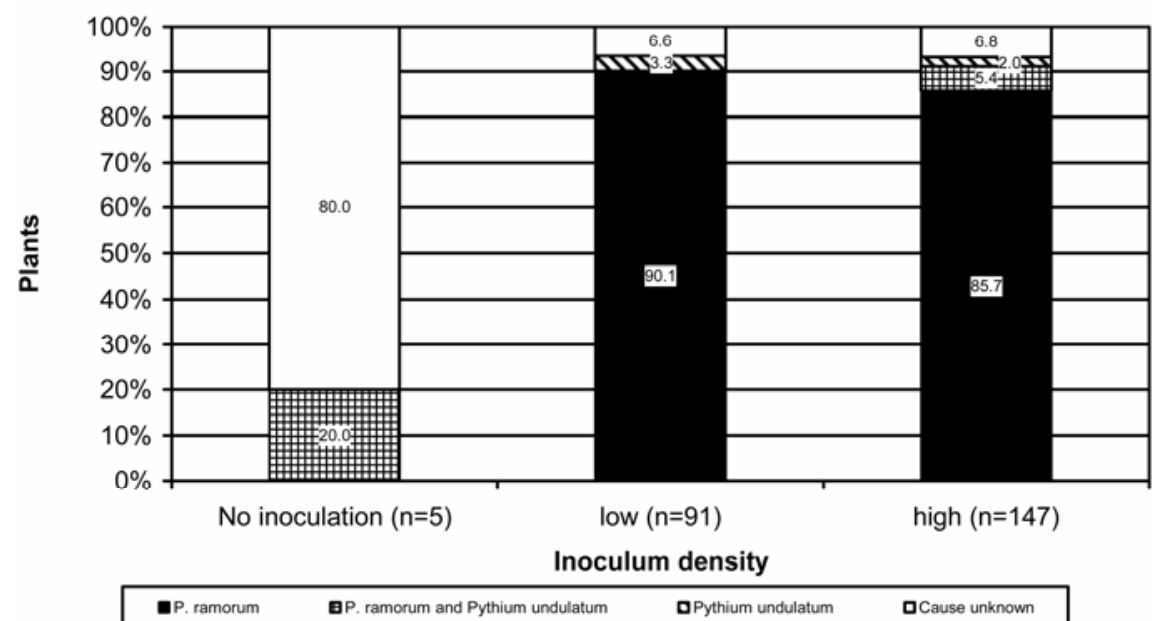

Fig. 2. Percentage of Phytophthora spp. or Pythium undulatum infection in the symptomatic Rhododendron $\mathrm{sp} . \mathrm{n}=$ total number of symptomatic Rhododendron. 
$P$ ramorum could not be detected in all symptomatic Rhododendron plants (Fig. 3). However, in symptomatic Rhododendron plants from treatments with infested water, $P$. ramorum generally could be detected. The highest detection rate among the plants showing disease symptoms was $91.1 \%$ in 2005 in the high-inoculumdensity treatment. In symptomatic Rhododendron plants from which $P$. ramorum could not be detected, there often was limited root development.

In 2004, the average number of diseased Rhododendron plants with $P$. ramorum was higher in the low-inoculum-density (7.1\%) than in the high-inoculum-density $(5.0 \%)$ treatments (Fig. 3). Also, four symptomatic plants from the noninfested treatment tested positive for $P$. ramorum. Due to the high variability (see below), the mean values were not significantly different among treatments and control. In 2005, the average percentage of Rhododendron plants that were symptomatic and shown to be infected by $P$. ramorum was higher than in 2004: $0.1 \%$ (no inoculation), $8.2 \%$ (low

\section{Experimental period May 2004 - March 2005}

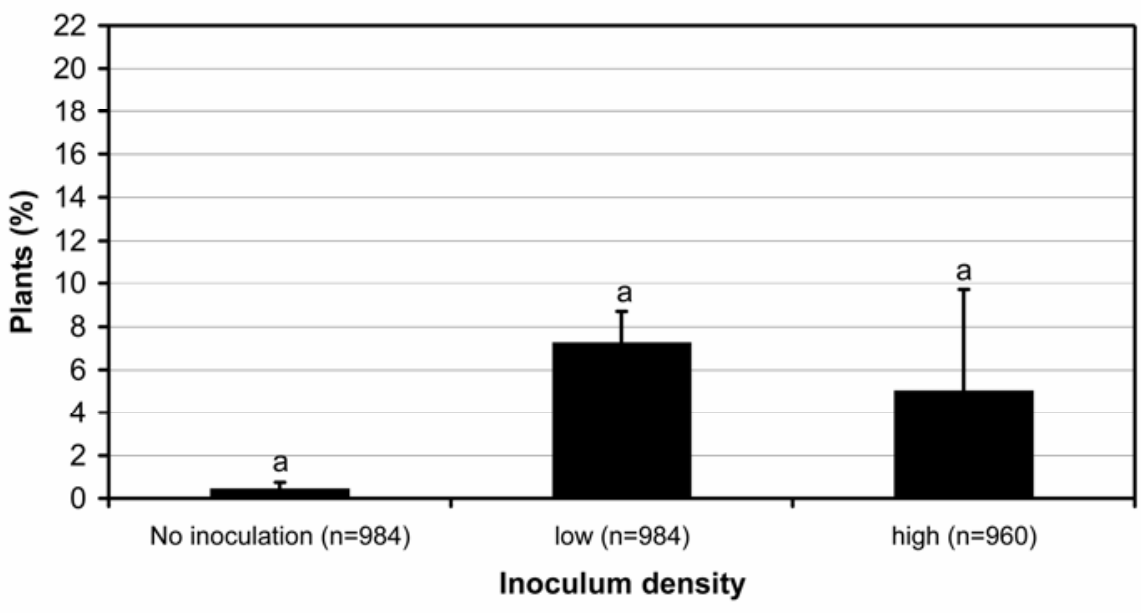

Experimental period May - November 2005

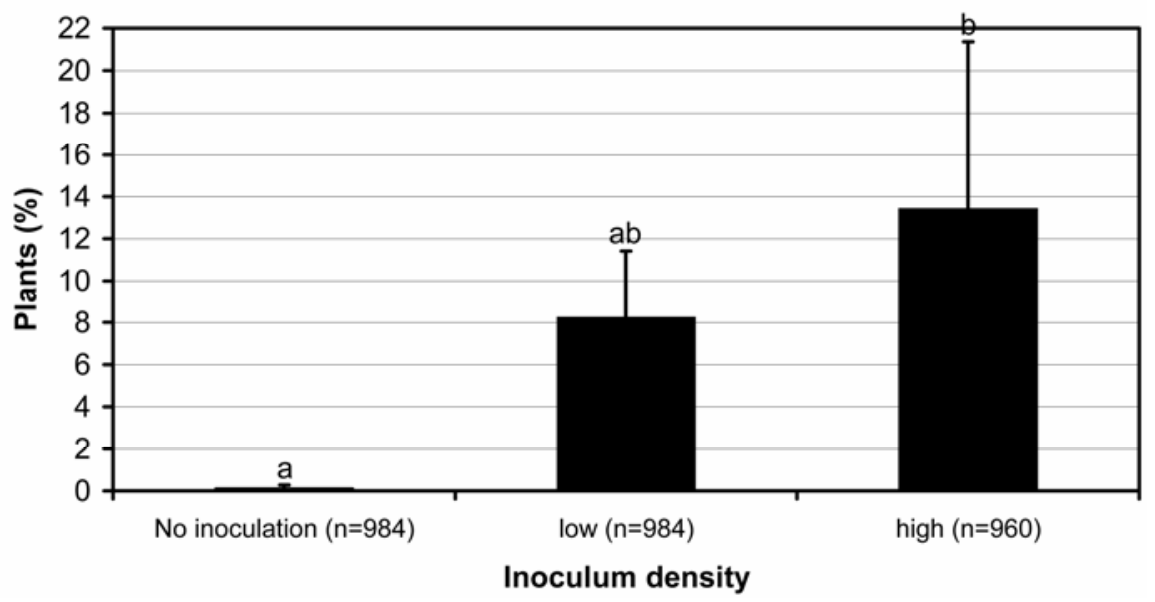

Fig. 3. Disease incidence for Rhododendron plants infected with Phytophthora ramorum. Bars with the same letter are not significantly different at $P=0.05$ (one way analysis, Tukey test). Total number (n) of plants in the experiment by treatment varied slightly across treatments.
Viburnum. In only two of the eight symptomatic Viburnum plants could Phytophthora ramorum be detected. These two plants were from container stand B of the high-inoculum treatment.

Seasonal symptom development and detection rates. Disease development varied between 2004 and 2005 (Fig. 4). In 2004, the first symptoms caused by $P$. ramorum occurred 7 days after the first irrigation with infested water. During this period, the water temperatures were above $15^{\circ} \mathrm{C}$ and air temperatures were approximately $15^{\circ} \mathrm{C}$ (Fig. 5). In 2005, initial symptoms were detected much later; 16 days after the first irrigation with infested irrigation water. Within a period of 5 days after infesting the reservoirs ( 8 June), the air temperatures were much lower than in 2004. However, they increased quickly up to a much higher level than in 2004 until the date of first symptom occurrence (24 June).

In 2004, the number of symptomatic plants and $P$. ramorum detections increased quickly up to the end of July, followed by a rapid decrease (Fig. 4). Up to the last sampling date in 2004 (midOctober), only a few additional plants developed disease symptoms and tested positive for $P$. ramorum. No further development of disease symptoms were observed on the Rhododendron plants in January 2005 and March 2005 before the plants were removed. However, two plants with disease symptoms were seen when the plants were checked visually for the final examination at the laboratory in March 2005. With the plants placed on the container stands in May 2005, two main periods were observed for disease development and for high detection rates of $P$. ramorum in these plants: one at the beginning of July and the second at the end of August (Fig. 4, experimental period May to November 2005).

Disease development was different on Rhododendron infected with $P$. cinnamomi. In contrast to the $P$. ramorum-infected plants, the occurrence of first disease symptoms was later (mid-August) and the period for symptom development was much shorter.

Relationship of symptom development and detection rates with precipitation and global radiation. In 2004, periods of heavy rainfall alternated regularly with dry periods except in summer, where a wet period occurred from the beginning of June until mid-July. In 2005, the alternating periods of dry and wet weather conditions were longer than in 2004. A longer period with rainfall occurred in July and August. The maximum precipitation was nearly identical in both years: 26.6 $\mathrm{mm} 24 \mathrm{~h}^{-1}$ on 21 September 2004 and 24.2 $\mathrm{mm} 24 \mathrm{~h}^{-1}$ on 21 July 2005 . In both years, no clear correlation between precipitation and occurrence of disease symptoms could be detected. 
Solar radiation also varied in the 2 years. In both years, high intensities of solar radiation occurred between May and August. In 2004, it ranged between 35.9
Wh $\mathrm{m}^{-2}$ (December 30) and 8,999.5 Wh $\mathrm{m}^{-2}$ (July 30). Solar radiation started to decrease early in September. In 2005, it ranged from $55.4 \mathrm{Wh} \mathrm{m}^{-2}$ on January 07 to
10,204.4 $\mathrm{Wh} \mathrm{m}^{-2}$ on 6 June. During autumn and early winter, the sum of solar radiation was much higher than in 2004.

There was no clear correlation between

\section{Experimental period May 2004 - March 2005}

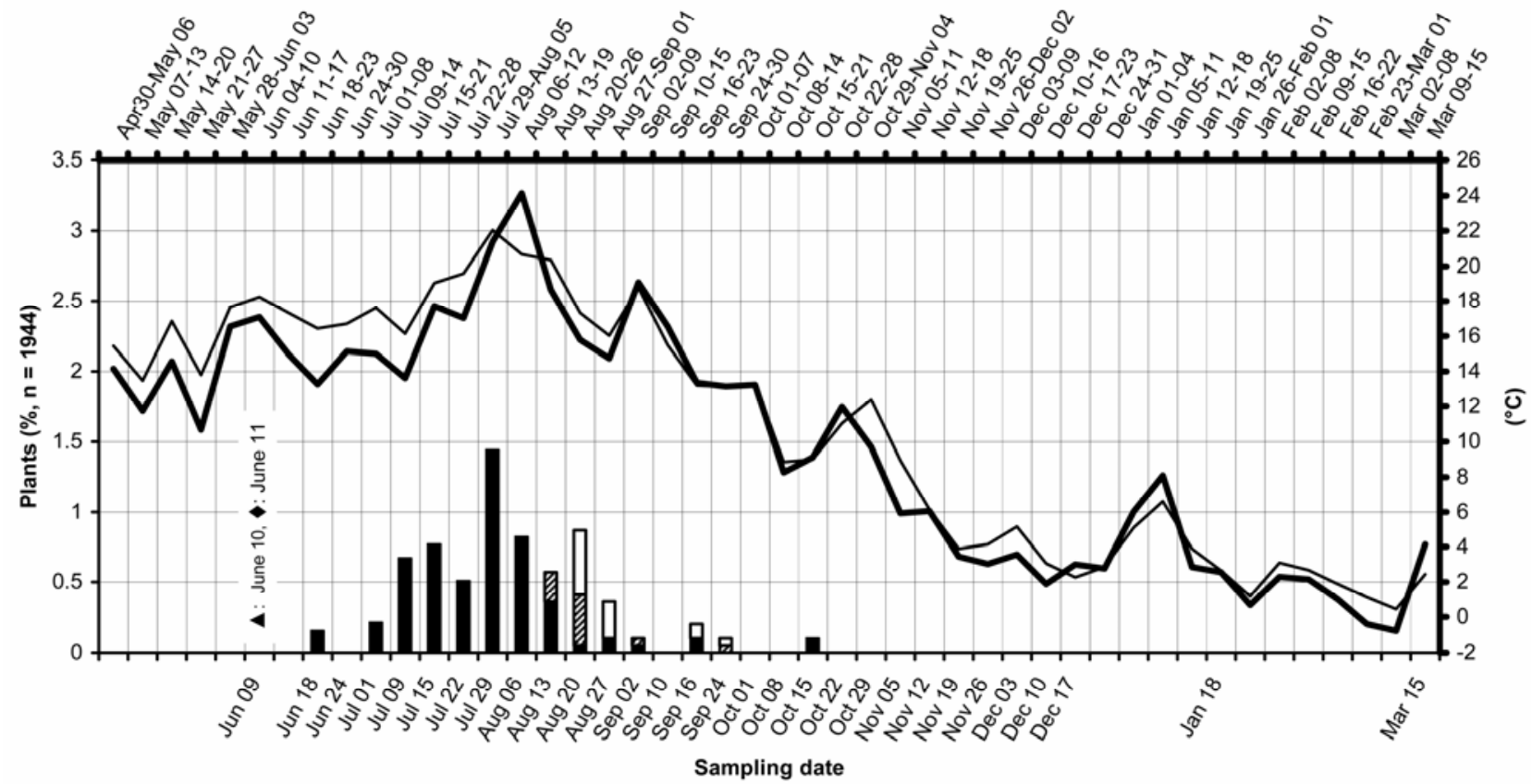

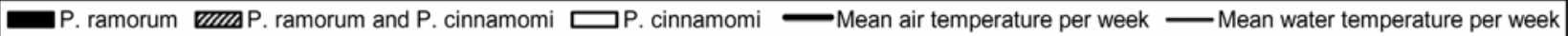

Experimental period May - November 2005
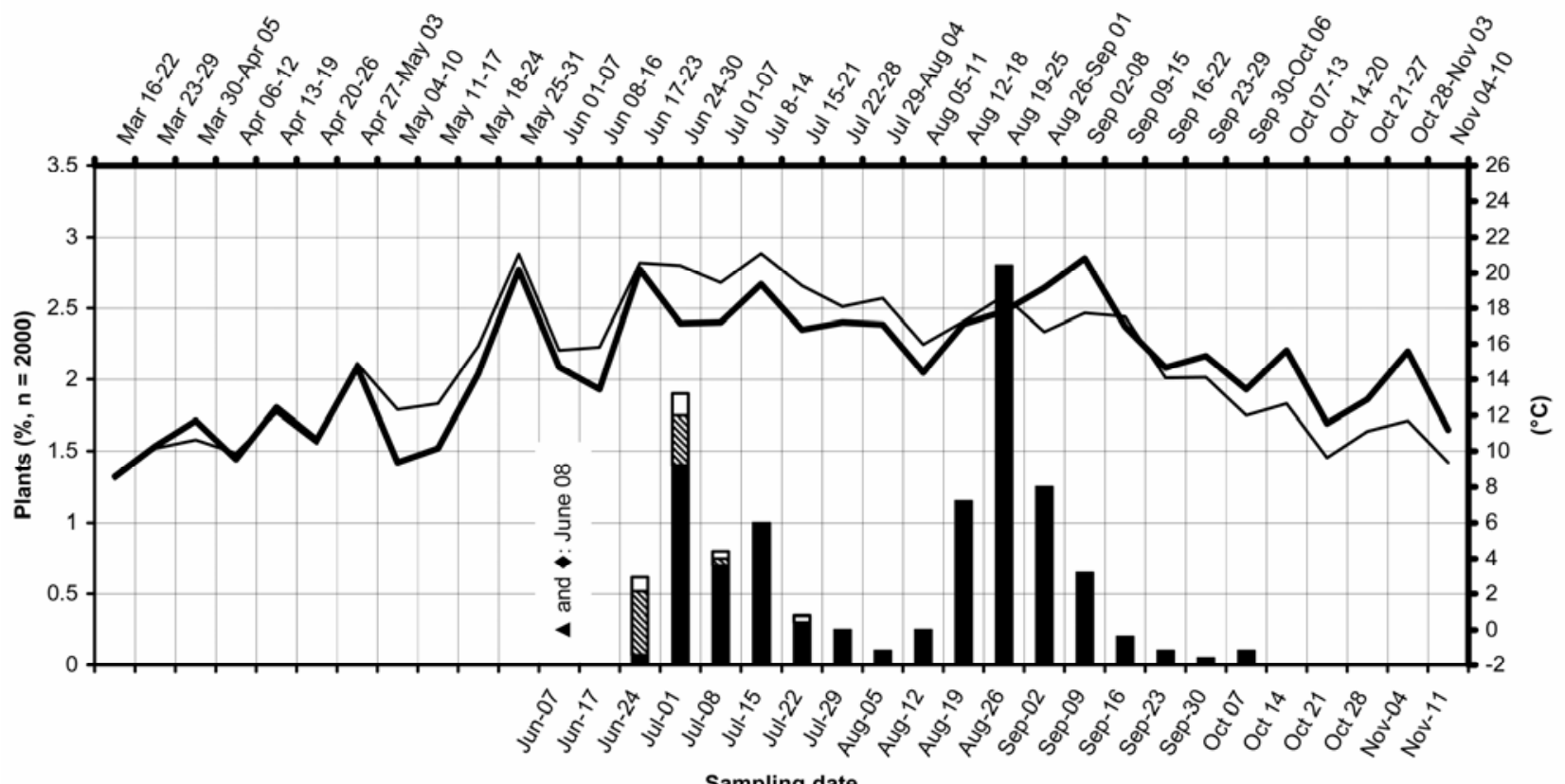

Sampling date

\section{Mean air temperature per week \\ Mivi ramorum and Phytium undulatum \\ Pythium undulatum}

$\boldsymbol{\Delta}=$ inoculation date of the water reservoirs

$\checkmark$ = first irrigation with infested water from the reservoirs

Fig. 4. Symptomatic Rhododendron plants with Phytophthora spp. or Pythium undulatum infection during the season. All Rhododendron in the first experiment were removed from the container areas in March 2005 and a new set was placed on the container areas later in May 2005 for the second experiment. Air temperature and water temperature (reservoirs) were recorded over the experimental periods. 
solar radiation and the number of symptomatic plants.

Distribution pattern of diseased Rhododendron plants on the container stands. In 2004 and in 2005, no clear infection pattern could be detected for $P$. ramorum with respect to wind direction or direction of water movement. However, in 2004, there were initial indications that Rhododendron plants originating from the nursery were preferentially infected, possibly because they had fewer roots. In contrast, the spread of infection with $P$. cinnnamomi started on a single plant and spread concentrically to the adjacent plants.

Plant quality and detection of $P$. ramorum in the root balls at the end

2004

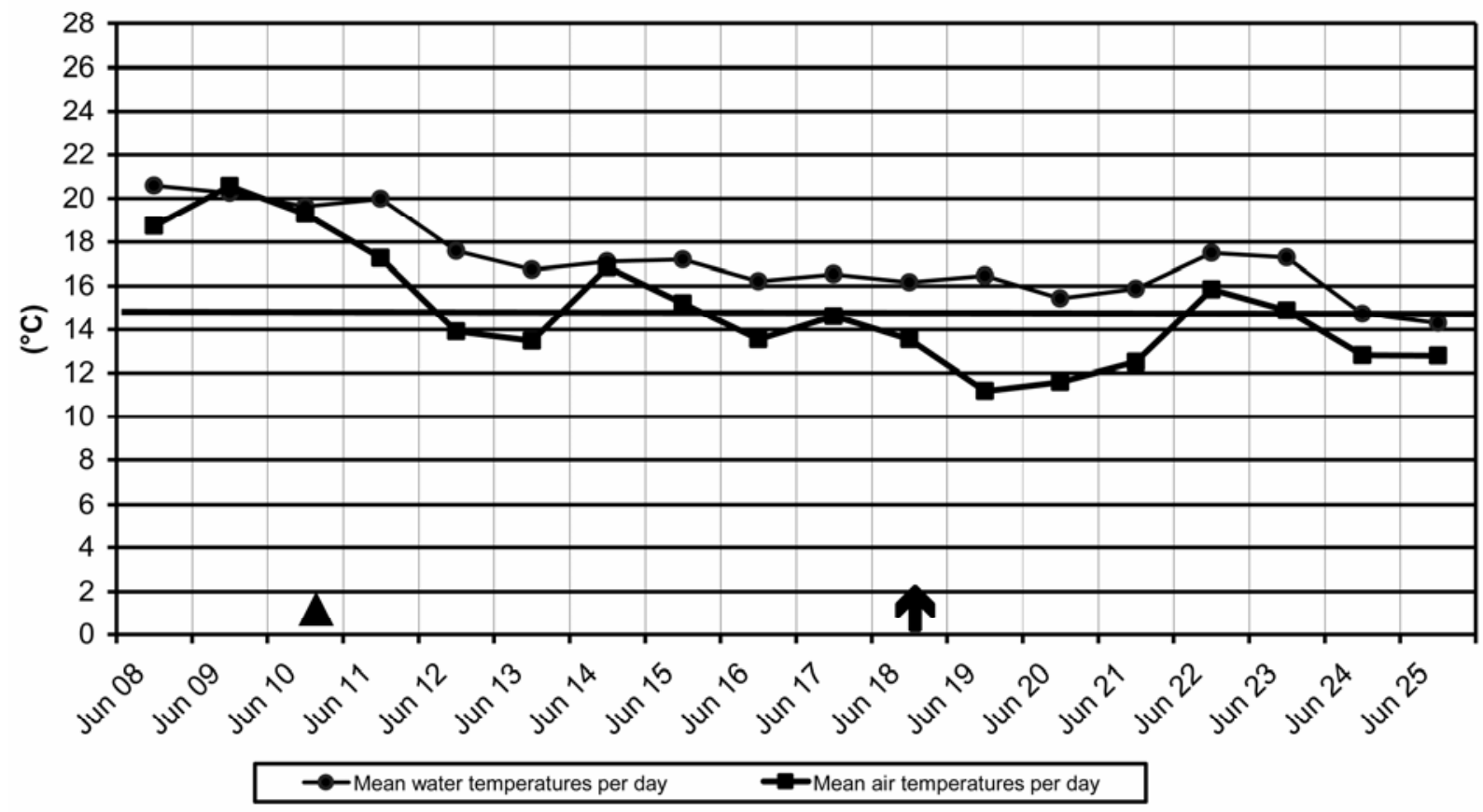

2005

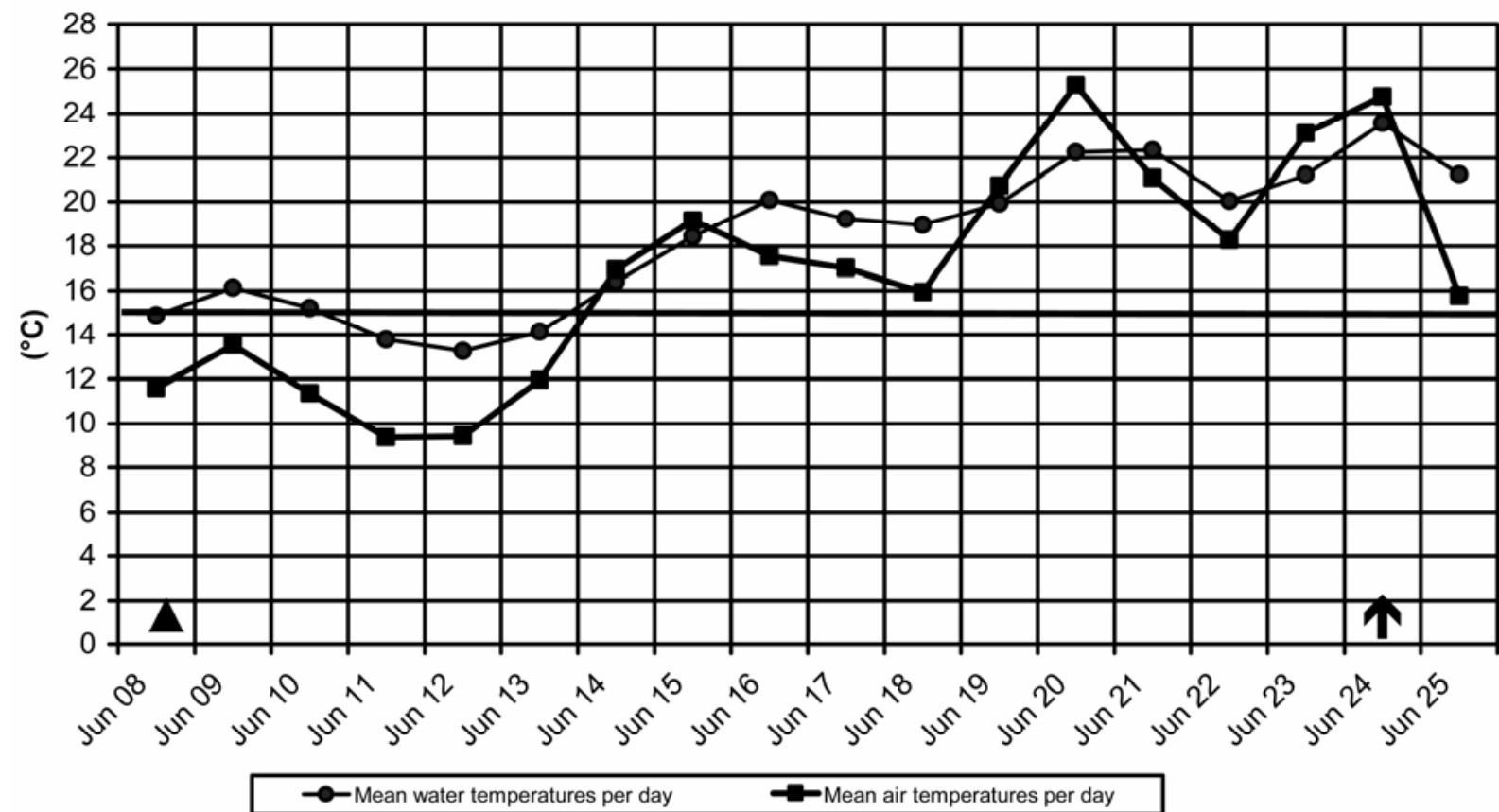

$\mathbf{\Delta}=$ Date of inoculation, $\boldsymbol{\mathbf { A }}=$ First occurrence of disease symptoms

Fig. 5. Average daytime temperatures from the date of infesting of the water reservoirs until the occurrence of first disease symptoms. 
of the experiment. Rhododendron removal March 2005. The 90 plants which were examined carefully showed a welldeveloped root system with three exceptions; 5 of the 30 Rhododendron plants which originated from the noninfested container stands ( 1 plant from stand $\mathrm{C}$ and 4 from stand A), and the wilting plant (see below) from the low-inoculum-density treatment (container stand B) had poor root growth. Among the 90 plants, a single plant with initial wilting symptoms, leaf spots on the leaves close to the stem base, and brown-colored roots was detected. None of the other Rhododendron plants showed disease symptoms on the upper parts or on the roots. From the bait test with the mixed root ball samples of the healthy-looking plants, $P$. ramorum could be detected in only one sample of the noninfested treatment and in one of the highinoculum-density treatments (Table 3). However, in these samples, detection was achieved only with PCR. There was no correlation between PCR result and root development. The single Rhododendron plant with disease symptoms from the lowinoculum-density container stand was infected with $P$. ramorum; direct isolation from the stem base and the Rhododendron leaf test with root ball samples gave positive results.

Rhododendron removal November 2005. These Rhododendron plants also were in good condition, with well-developed root systems. The average number of shoots per plant varied between 2.1 (high inoculum density) and 2.4 (not inoculated) and the average shoot length ranged from $25.2 \mathrm{~cm}$ (high inoculum density) to $26.3 \mathrm{~cm}$ (not inoculated). In terms of the number of shoots and the shoot length, there were no significant differences between the three variants. However, there was a significant difference in shoot length regarding the plant position on the container stands in the high-inoculum-density treatment; Rhododendron plants close to a previously detected diseased plant had longer shoots than the plants distant from an infected one. However, these differences were not relevant for commercial practice.

Among the 776 Rhododendron plants taken to the laboratory, only 2 had foliar symptoms. These two plants originated from two container stands of the lowinoculum-density treatment. They showed discoloration of the leaf base starting at the petiole and at the stem base, but the roots appeared healthy.

$P$. ramorum was detected in the root ball samples of the healthy-appearing Rhododendron plants from one of the lowinoculum-density and from two of the high-inoculum-density container stands (Table 4). On these container stands, only the plants close to a previously detected infected Rhododendron plant tested positive. In the noninfested treatment, the samples from water reservoir $\mathrm{C}$ were positive based on PCR but negative based on direct isolation from the baits. From the two Rhododendron plants with disease symptoms, $P$. ramorum could be isolated directly and baited from the root balls. In all root ball samples, Pythium undulatum was present.

Viburnum. At the end of the season, the Viburnum plants appeared healthy, with a number of lateral branches of first order per plant varied between 3.4 (not infested) and 3.9 (low inoculum density) and that of second order between 2.7 (low inoculum density) and 3.2 (not infested). The data were not significantly different.

Of the 448 Viburnum plants taken to the laboratory, 5 showed disease symptoms on the upper parts; 4 had damage on twigs and 1 had died and showed a cambium had brown-colored roots. The healthyappearing Viburnum plant as well as the four Viburnum plants with twig symptoms had healthy-looking root systems. All five Viburnum plants with disease symptoms originated from the noninfested container stands (reservoir A and B).

From nearly all root ball samples prepared from the healthy-appearing Viburnum plants originating from the infested container stands, Phytophthora ramorum could be baited with Rhododendron leaves in November 2005 (Table 4). Detection was negative with the symptomless Viburnum plants from the noninfested stands. In the four Viburnum plants which showed twig symptoms and in the single Viburnum plant with the discolored stem base and roots, $P$. ramorum could not be detected in either the discolored tissues or the root balls.

\section{DISCUSSION}

This study has demonstrated that $P$. ramorum can survive in and spread with well-developed root system. The average necrosis at the stem base. This plant also

recirculation water under the conditions of these experiments and in the climate conditions of Western Europe.

Survival of $P$. ramorum in the water reservoirs occurred during all seasons, including the two winter periods. It is possible that inability to survive is the explanation for the negative results of the bait test conducted in April 2004 in the three control reservoirs which were demonstrated to be contaminated with $P$. ramorum in the pretest in December 2003. However, it is more likely that the pathogen had survived in these reservoirs because $P$. ramoruminfected Rhododendron plants were detected on the corresponding container stands of the control reservoirs in 2004 and in 2005. Perhaps the inoculum density was too low (see below) for detection by baiting infection after the winter of 2003-04.

There is no information on the number of chlamydospores, sporangia, and zoospores or on the ecology of these propagules in the simulation system used for these studies. It also is not known whether only zoospores circulated in irrigation water from the reservoirs to the plants and from the container stands back to the reservoirs. Nevertheless, results from the present study can help with creating a preliminary idea about the development of $P$. ramorum in a water recirculation system and on influencing factors. The baiting results in the reservoirs indicate that the presence of $P$. ramorum in the water reservoirs varied with the season. Seasonal variation in the range of Phytophthora spp. and in the number of isolates in the water reservoirs of commercial nurseries is known (15). In 2005, the greatest number of detections was obtained between August and November, when $P$. ramorum could be trapped from all infested water reservoirs. These results did not correlate in every case with the corresponding trapping period. Lack of

Table 3. Detection of Phytophthora ramorum and Pythium undulatum in the root balls of asymptomatic Rhododendron plants removed in March 2005 (experimental period May 2004 to March 2005)

\begin{tabular}{|c|c|c|c|c|c|}
\hline \multirow[b]{3}{*}{ Density $^{b}$} & \multirow[b]{3}{*}{ Water reservoir ${ }^{c}$} & \multirow[b]{3}{*}{$n^{\mathrm{c}}$} & \multicolumn{3}{|c|}{ Detection of $^{\text {a }}$} \\
\hline & & & \multicolumn{2}{|c|}{ Phytophthora ramorum } & \multirow{2}{*}{$\begin{array}{c}\text { Pythium undulatum } \\
\text { DI }\end{array}$} \\
\hline & & & DI & PCR & \\
\hline \multirow[t]{3}{*}{$\mathrm{NI}$} & A & 10 & $\varnothing$ & $\varnothing$ & + \\
\hline & B & 10 & $?$ & + & + \\
\hline & $\mathrm{C}$ & 10 & $\varnothing$ & $\varnothing$ & + \\
\hline \multirow[t]{4}{*}{ Low } & A & 10 & $\varnothing$ & $\varnothing$ & + \\
\hline & B & 9 & $\varnothing$ & $\varnothing$ & + \\
\hline & $\ldots$ & $1 *$ & + & + & + \\
\hline & $\mathrm{C}$ & 10 & $\varnothing$ & $\varnothing$ & $\varnothing$ \\
\hline \multirow[t]{3}{*}{ High } & A & 10 & $\varnothing$ & + & + \\
\hline & B & 10 & $\varnothing$ & $\varnothing$ & $\varnothing$ \\
\hline & $\mathrm{C}$ & 10 & $\varnothing$ & $\varnothing$ & + \\
\hline
\end{tabular}

${ }^{\mathrm{a}} \mathrm{DI}=$ direct isolation from the bait leaves, $\mathrm{PCR}=$ polymerase chain reaction from agar culture and bait leaves, $\varnothing=$ detection negative,$+=$ detection positive, and $?=$ separation between Phytophthora ramorum and Pythium undulatum not possible.

${ }^{\mathrm{b}}$ Density $=$ inoculum density and NI = not inoculated.

c Number of asymptomatic plants $(n)$ which were pooled for leaf bioassay. One plant in replication B of the low inoculum density was symptomatic at time of sampling (*). 
detection in some reservoirs and rapid detection in others during the same sampling period could indicate a lack of chlamydospores or sporangia in the reservoirs that tested negative, but a quick release of zoospores from sporangia present in those that tested positive. It seems that low temperatures during winter decreased the inoculum in the water reservoirs. The negative baiting results for some of the reservoirs at the beginning and at the end of May indicate that development of new sporangia from the resting spores can take months. The negative baiting results in some of the infested reservoirs in July and in two of the low-inoculum-density reservoirs in August 2005 also indicate that, even in summer, it can take several weeks until large numbers of new sporangia develop. Inoculation of the reservoirs in June did not increase the baiting success rate in July. It is most likely that the sporangia from the agar cultures released the zoospores within a short period after the inoculation of the reservoirs in June. Those zoospores which did not reach the plants by overhead irrigation must have died or encysted in the water reservoirs, so they could not reach the bait leaves in the July bait test. Large numbers of new sporangia and new zoospores must have been present again at the end of July and beginning of August; earlier in the reservoirs of high inoculum density than in those of low inoculum density. And, during the second half of the year, it appears that $P$. ramorum became established in all infested reservoirs in sufficient concentrations for detection by baiting. The data also indicate that sporangia and zoospore development was possible until November or December.

Different factors can influence sporangia production and zoospore release in the reservoirs. One of the major influencing factors seems to be the water temperature. Temperatures above $15^{\circ} \mathrm{C}$ seem to favor the release of zoospores, as discussed above, or the production of sporangia. Temperatures between 15 and $20^{\circ} \mathrm{C}$ are known to be favorable for sporangia development on foliar hosts (3). However, the water temperature did not explain differ-

Table 4. Detection of Phytophthora ramorum and Pythium undulatum in the root balls of asymptomatic plants removed in November 2005 (experimental period May-November 2005)

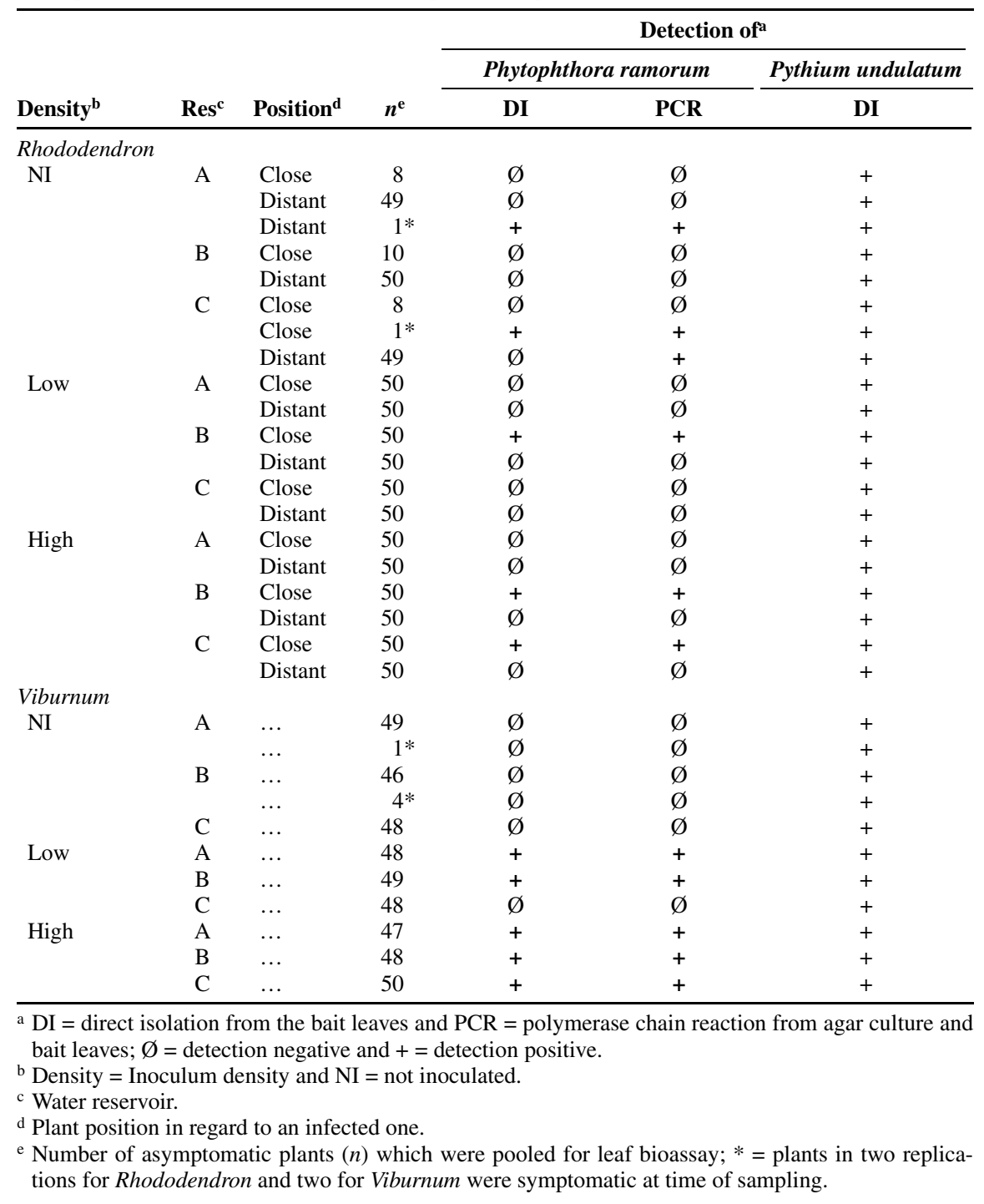

ences in the detection results in the three water reservoirs infested with the same inoculum density. Different water replenishment times diluted the zoospore concentrations but the data did not show a clear correlation between the date and volume of replenishment and the proportion of diseased and infected Rhododendron plants. It also may be that the growth of algae in some of the reservoirs influenced $P$. ramorum. Other factors could be differences in the range of antagonistic microorganisms. It would be valuable to determine the cause or causes of the variability to use for nonchemical suppression of $P$. ramorum in water reservoirs.

In contrast to the results of an earlier study where infection of Rhododendron plants via irrigation with contaminated stream water failed (17), the results of the present study clearly indicate that $P$. ramorum can be spread with contaminated water and that infection via overhead irrigation is possible. The differing results may be due to differing inoculum densities.

The maximum amount of $P$. ramoruminfected Rhododendron plants that developed disease symptoms was below $19 \%$. This is low compared with some other Phytophthora spp. One possible explanation is that the inoculum density usually was not high enough to cause symptoms. Calculation of zoospore release from the sporangia present on the agar cultures used for inoculation of the water reservoirs showed that a maximum of $5.9 \times 10^{6}$ zoospores per Petri dish (9.5 cm in diameter) could be released within hours (S. Wagner and S. Werres, unpublished data). That would mean that a zoospore concentration between $7.4 \times 10^{7}$ (low inoculum density, 2004 and 2005) and $3.0 \times 10^{8}$ (high inoculum density, 2005) could have been present in a single water reservoir (1,000 liters) at the date of the first irrigation. With overhead irrigation, a zoospore concentration below 74 zoospores $\mathrm{ml}^{-1}$ seems to be sufficient for initial infection of Rhododendron plants. It seems to be not sufficient to infect the Viburnum cultivar. Tooley et al. (18) found that Kalmia latifolia and Arctostaphylos uva-ursi did not show any disease symptoms when they were infested with less than 50 sporangia/ml. Another reason for the low infection rates could be a low susceptibility of the Rhododendron and Viburnum plants used in the studies. It was surprising that the Rhododendron cultivar was infected more easily than $V$. plicatum Mariesii, a cultivar from which $P$. ramorum had been isolated in a European nursery. This cultivar may be less susceptible than $V$. bodnantense Dawn. Another consideration could be that the ultraviolet part of the daylight in this geographical area influenced or inactivated zoospore germination or the germinating hyphae, which would reduce the amount of viable inoculum on the plants. Results of 
in vitro studies with different Phytophthora spp. indicate that, in general, shorter-wavelength treatments enhance sporangia production whereas longer wavelengths stimulate oospore production (13). In addition, sporangia produced under near-UV radiation differentiated and released fewer zoospores. However, the results varied with the Phytophthora sp. and also with the isolate. Initial studies with $P$. ramorum indicate that the influence of different wavelengths also depends on the isolate but that the pathogen appears to be tolerant toward a wide range of environmental conditions (6)

Variation in length of time between inoculation of the water reservoirs and the first occurrence of disease symptoms on Rhododendron plants in 2004 and 2005 very likely also is caused by lower numbers of active zoospores in the water reservoirs when temperatures were low. Although the initial overhead irrigation after inoculation of the water reservoirs was later in 2004 than in 2005, and heavy rainfall in the first week of overhead irrigation in 2004 could have washed off zoospores from the leaves, the first diseased Rhododendron plant infected by $P$. ramorum was detected much earlier in 2004 than in 2005. It is very likely that, in 2005 , the very low temperatures on the days after the inoculation of the water reservoirs were not favorable for zoospore release. That sporangia were present in high numbers could be seen when the cultures in the petri dishes used for infesting the reservoirs were examined microscopically.

Most likely, the number of diseased and infected Rhododendron plants reached a maximum at the end of July 2004 and at the beginning of July 2005 due to inoculation of the reservoirs in June. The subsequent decrease in infection rate followed by a second maximum in number of diseased and infected plants at the end of August 2005 more likely was due to an increase in the quantity of sporangia and zoospores in the water reservoirs than to the late development of disease symptoms after an early infection. It may be that new sporangia developed from chlamydospores which were present on the agar cultures used for inoculation or developed in the root balls of the irrigated Rhododendron plants It seems that, during the first half of the year, the number of zoospores in the reservoirs and the infection rates correlated. However, during the second half of the year, other factors must have influenced the infection rate or the development of disease symptoms. The results of the bait tests clearly showed that zoospores were present in all infested reservoirs. However, in 2004 and 2005, the infection rates with $P$. ramorum decreased in late summer and autumn. In both years, the decrease of infection rates coincided with continuous decrease in temperature. It may be that the changing physiology of Rhodo- dendron plants with development of new buds and termination of shoot growth in late summer to early autumn influences symptom development, perhaps also susceptibility to $P$. ramorum. Seasonal trends also were detected in infection trials with branch cuttings collected during different months (5). The authors assume that development of the cambium and the correlated sugar contents in the phloem have a major influence on lesion size throughout the year.

For nurseries, one of the most important questions about $P$. ramorum is that of latency. The marketing of asymptomatic but infected plants is suspected to be responsible for the international spread of $P$. ramorum. Our results show that disease symptoms can develop in summer between 8 and 16 days after inoculation. Higher temperatures might speed up symptom development. There is the question of whether $P$. ramorum was present only in the soil of the root balls or whether it also caused root infection. Recent studies with Rhododendron plants showed the presence of asymptomatic root infection caused by $P$. ramorum $(2,8,12)$. If detection of $P$. ramorum in some of the root ball samples of the healthy-appearing Rhododendron and Viburnum plants really means not only soil infestation but also root infection, this would indicate that latency can be very long. Linderman (9) detected that $P$. ramorum survived in different potting soils for at least 6 months. Due to either of these factors, the results may explain why healthy-appearing plants can suddenly develop disease symptoms caused by $P$. ramorum. The results confirm the data from Parke et al. (11), who detected $P$. ramorurm not only in potting media but also in symptomless Rhododendron tissue.

The presence of $P$. ramorum in the noninfested reservoirs indicates that the pathogen had spread from the infested reservoirs. It is impossible to determine how the spread occurred; however, contaminated water drops could have been transported with the wind during overhead irrigation. Spread of contaminated water drops during irrigation seems to be the main factor in the simulation system and not the spread from plant to plant. As soon as the plants showed disease symptoms, they were removed. However, considering the very low number of Rhododendron plants with disease symptoms and $P$. ramorum infection on these container stands, the inoculum density in the noninfested reservoirs must have been very low. It cannot be excluded that, in principal, spread from plant to plant is possible if infected plants remain on a container stand. This could be identified easily because a nested pattern would develop around the plant with the first infection. However, the distinct nested pattern of infected plants that develops around an initial infected plant did not occur with
$P$ ramorum in the infested experiments. However, it was seen with the single container stand with Rhododendron infected with $P$. cinnamomi in 2004 . This suggests that infection occurred early during propagation, started on one or more rooted cuttings, and spread to the neighboring cuttings. The infection with $P$. cinnamomi remained latent until August, when the high temperatures favoured symptom development.

There is the question of why pathogen spread via overhead irrigation did not result in disease symptoms mainly on the twig tips and upper leaves. The main disease symptoms on Rhododendron plants were a discoloration of the stem base and leaves close to the soil surface. Four possible explanations have been identified. First, the upper leaves and twig parts of Rhododendron plants usually dry more quickly than the stem base. That means the amount of free water and high humidity is much greater and remains for a longer period near the soil surface than near the twig tips. Second, an accumulation of $P$. ramorum propagules after overhead irrigation is much more likely on the soil surface or in the root ball than in the upper parts of the plant. Third, the low $\mathrm{pH}$ of the soil substrate could favor sporangia and zoospore development. That means that the most favorable conditions for $P$. ramorum development and infection would occur on the soil surface in the containers. Another possible factor is that the higher intensity of ultraviolet light occurring in the upper than lower parts of the plants perhaps kills or inhibits zoospore germination or penetration into leaf or bud tissue. The Rhododendron plants were not in shade in the simulation system.

This study has provided initial results regarding spread of $P$. ramorum with contaminated irrigation water under the climatic conditions of Western Europe. Further studies are needed to investigate the latency period and conditions favoring infection and symptom development. It also would be important to know whether there is a threshold for the inoculum density in water in order for plant infection to occur. And it would be helpful to have more knowledge about development of $P$. ramorum in water. The present study was a first step to evaluate the risk of infection by using recirculation water for overhead irrigation. Studies on contamination rates, on the number and kind of $P$. ramorum propagules in the irrigation and recirculated water of commercial nurseries, and on their pathogenicity are needed to verify the results for commercial practice.

\section{ACKNOWLEDGMENTS}

We thank the United States Department of Agriculture Forest Service, Pacific Southwest Research Station, and the European Commission for funding of the project; D. Cooke (SCRI, UK) for the validation of the Pythium undulatum isolates with molecular methods; J. Hauffe and A. Haverlah for 
excellent technical assistance; P. Tooley for stimulating discussion; and the two anonymous reviewers for their helpful comments.

\section{LITERATURE CITED}

1. Bärtels, A. 1985. Der Baumschulbetrieb. Eugen Ulmer $\mathrm{GmbH}$ \& Co. Stuttgart, Germany. 600:82-85.

2. Bienapfl, J. Zanzot, J. W., Murphey, S. D., Garbelotto, M., and Rizzo, D. M. 2005. Isolation of a new lineage of Phytophthora ramorum from asymptomatic stems and roots of a commercial lot of rhododendron in California. Phytopathology 95:20.

3. Davidson, J. M., and Shaw, C. G. 2003. Pathways of movement for Phytophthora ramorum, causal agent of sudden oak death. American Phytopathological Society Sudden Oak Death Online Symposium.

4. Davidson, J. M., Werres, S., Garbelotto, M., Hansen, E. M., and Rizzo, D. M. 2003. Sudden oak death and associated diseases caused by Phytophthora ramorum. Online. Plant Health Progress doi: 10.1094/PHP-2003-0707-01-DG.

5. Dodd, R., Huberli, D., Harnik T., O'Dell, B., and Garbelotto, M. 2005. Seasonal trends in response to inoculation of coast live oak with Phytophthora ramorum. Sudden Oak Death Science Symposium II, Monterey, CA. Gen. Tech. Rep. PSW-GTR-196:125-127.

6. Englander L., Browning M., and Tooley, P. Growth and sporulation of Phytophthora ramorum in vitro in response to temperature and light. Mycologia. In press.

7. Krüssmann, G. 1997. Pages 639-662 in: Die
Baumschule. Parey Buchverlag, Berlin.

8. Lewis, C. D., Roth, M. L., Choquette, C. J., and Parke, J. L. 2004. Root infection of rhododendron by Phytophthora ramorum. (Abstr.) Phytopathology 94:60.

9. Linderman, R. G., and Davis, E. A. 2005. Survival of Phytophthora ramorum compared to other Phytophthora species in potting media components or soils. Sudden Oak Death Science Symposium II, Monterey, CA. Gen. Tech. Rep. PSW-GTR-196:265-268.

10. Over, G. 1981. Wasserwiederverwendung in Containerquartieren. Dtsch. Gartenbau 5:164.

11. Parke, J. L., Roth, M., and Choquette, C. 2005. Phytophthora ramorum disease transmission from infested potting media. Sudden Oak Death Science Symposium II, Monterey, CA. Gen. Tech. Rep. PSW-GTR-196:291293.

12. Parke, J. L., Roth, M. L., Lewis, C., and Choquette, C. J. 2006. Infection of Rhododendron macrophyllum roots, stems, and leaves by soilborne inoculum of Phytophthora ramorum. In: Progress in Research on Phytophthora Diseases of Forest Trees. C. Brasier, T. Jung, and W. Oswald, eds. Proc. 3rd Int. IUFRO Working Party S07.02.09. Forest Research, Farnham, Surrey, UK.

13. Ribeiro, O. K., Zentmyer, G. A., and Erwin, D. C. 1976. The influence of qualitative and quantitative radiation on reproduction and spore germination of four Phytophthora species. Mycologia 68(6):1162-1173.

14. Themann, K., Werres, S., Diener, H.-A., and Lüttmann, R. 2002. Comparison of different methods to detect Phytophthora spp. in recycling water from nurseries. J. Plant Pathol 84(1):41-50.

15. Themann, K., Werres, S., Diener, H.-A., and Lüttmann, R. 2002. Epidemiology of Phy tophthora spp. in water recycling systems of commercial nurseries. Eur. J. Plant Pathol. 108(4):337-343

16. Tjosvold, S. A., Chambers, D. L., Davidson, J. M., and Rizzo, D. M. 2002. Incidence of Phy tophthora ramorum inoculum found in streams running through areas of high incidence of sudden oak death in Santa Cruz County. Sudden Oak Death Science Symposium, Monterey, CA.

17. Tjosvold, S. A., Chambers, D. L., and Fichtner, E. 2006. Epidemiology of Phytophthora ramorum infecting rhododendrons under simulated nursery conditions. Proc. Sudden Oak Death Second Sci. Symp. State of our Knowledge. Monterey, CA. Gen. Tech. Rep. PSW GTR-196:459-461.

18. Tooley, P. W., Kyde, K. L., and Englander, L. 2004. Susceptibility of selected ericaceous ornamental host species to Phytophthora ramorum. Plant Dis. 88:993-999.

19. Werres, S., Marwitz, R., Veld, W. A. M. I., De Cock, A. W. A. M., Bonants, P. J. M., De Weerdt, M., Themann, K., Ilieva, E., and Baayen, R. P. 2001. Phytophthora ramorum sp. nov., a new pathogen on Rhododendron and Viburnum. Mycol. Res. 105:1155-1165.

20. Whitcomb, C. E. 1988. Plant Production in Containers. Lacebark Publications, Stillwater, OK. pp. 290-295. 